\title{
Optimalisasi Neural Network dengan Bootstrap Aggregating (Bagging) untuk Penentuan Prediksi Harga Listrik
}

\author{
Oman Somantri ${ }^{1}$, Ginanjar Wiro Sasmito ${ }^{2}$, Muchamad Sobri Sungkar ${ }^{3}$, \\ Erwadi $^{4}$ \\ ${ }^{1,2}$ Program Studi Teknik Informatika, Politeknik Harapan Bersama, Tegal \\ ${ }^{3}$ Program Studi Teknik Elektro, Politeknik Harapan Bersama, Tegal \\ ${ }^{4}$ Program Studi Teknik Komputer, Politeknik Harapan Bersama, Tegal \\ Email: 'oman_mantri@yahoo.com, ${ }^{2}$ anjar.dosen@gmail.com, ${ }^{3}$ sobrisungkar@gmail.com, \\ 4erwadi@ymail.com
}

\begin{abstract}
Abstrak
Memprediksi harga listrik merupakan sebuah faktor penentu pendukung keputusan dalam mengeluarkan sebuah kebijakan pemerintah dalam menentukan harga listrik. Ketepatan akurasi prediksi sebuah prediksi harga listrik menjadi hal yang sangat diperhitungkan, dengan menggunakan Neural Network prediksi harga listrik diprediksi dengan harapan menghasilkan tingkat akurasi yang baik. Neural Network masih mempunyai kelemahan dalam menentukan nilai bobot terbaik sehingga optimalisasi dilakukan dengan menerapkan bagging kedalam model yang diusulkan. Berdasarkan hasil penelitian didapatkan bahwa penerapan bagging pada Neural Network dapat meningkatkan tingkat akurasi prediksi dengan nilai RMSE sebesar 10.513. Maka dapat disimpulkan bahwa prediksi harga listrik dengan mengggunakan bagging pada Neural Network lebih akurat dibandingkan dengan Neural Network tradisional.
\end{abstract}

Kata Kunci: bagging, harga listrik, Neural Network

\section{PENDAHULUAN}

Sejak awal tahun 1990-an proses deregulasi di pasar dunia telah membentuk sebuah aturan perdagangan pada sektor listrik dan dalam hal ini pemerintah sendiri menjadi pengendalinya. Di banyak negara di seluruh dunia, listrik kini diperdagangkan dibawah aturan pasar menggunakan spot dan kontrak derivative, namun listrik yang merupakan komoditi sangat istimewa ini membutuhkan keseimbangan yang konstan antar produksi dan konsumsi untuk menjaga stabilitas sistem tenaga dan perekonomian [1].

Perkiraan harga listrik merupakan salah satu faktor penting di pasar listrik. Keakurasian dalam peramalan dan prediksi harga listrik sangat berguna sekali bagi pelaku pasar dalam memutuskan sebuah keputusan dan manajemen resiko dalam prediksi harga listrik. Selain itu bagi pemasok listrik, prediksi harga listrik adalah acuan dasar untuk membangun strategi penawaran listrik yang optimal sedangkan bagi konsumen, untuk membantu mereka untuk mendapatkan jadwal dalam memperoleh pembelian listrik dengan daya listrik yang maksimum dengan biaya pengeluaran yang minimum [2].

Sebuah kebijakan yang tepat dalam sektor migas terutama dalam menetapkan harga listrik sangat berpengaruh sekali terhadap suatu perekonomian suatu Negara. Oleh 
karena itu penetapan suatu harga listrik harus diperhitungkan dengan matang dan disesuaikan dengan pendapatan masyarakat suatu negara serta keadaaan perekonomian negara tersebut. Perkiraan yang akurat dari penetapan harga listrik merupakan faktor yang sangat penting untuk membuat sebuah kebijakan migas dari sebuah negara. Sebuah analisis peramalan harga listrik disertai dengan teknik peramalan yang tepat sangatlah diperlukan tentunya akan bisa memberikan perkiraan yang akurat dalam memprediksi harga listrik, sehingga para pengambil kebijakan dalam hal ini pemerintah bisa membuat sebuah kebijakan terkait dengan perkiraan harga listrik.

Penelitian mengenai prediksi harga listrik ini sudah pernah dilakukan dengan menggunakan berbagai macam teknik, seperti artificial Neural Network (ANN), fuzzy inference system (FIS), support vector machines (SVM), ARIMA dan model GARCH. Dari beberapa penelitian yang digunakan untuk peramalan harga listrik terutama untuk prediksi jangka pendek, ANN sekarang ini lebih popular karena berdasarkan latar belakang teori serta performance prediksinya sangat memuaskan [2].

B. R. Szkuta, dkk melakukan penelitian dengan menerapkan tiga lapisan backpropagation Neural Network $(B P N N)$ untuk memprediksi harga marginal pasar (MMPs) di Victoria Australia [3]. Rodriguez dan Anders [4] serta Amjady [5] melakukan penelitian dengan menerapkan fuzzy Neural Network (FNN) untuk prediksi harga clearing market $(M C P)$ di pasar listrik Ontario dan Spanyol. Penelitian dilakukan oleh Meng, dkk., dengan menerapkan Radial Basis Function Neural Network (RBFNN) untuk memprediksi harga $(M C P)$ di pasar listrik Queensland [6].

Metode bagging adalah metode resampling yang telah berhasil diterapkan pada area supervised learning untuk meningkatkan akurasi prediksi [7]. Bagging (bootstrap aggregating) adalah salah satu metode ensemble yang cara kerjanya adalah membuat beberapa sampel data baru dari data latih asli sehingga menghasilkan data latih terbaik untuk membuat model yang ada [8]. Dari beberapa penelitian yang telah dilakukan sebelumnya, hasilnya menunjukan bahwa Neural Network memiliki hasil tingkat akurasi yang baik, namun dalam hal ini masih perlu ditingkatkan lagi agar performa algoritma yang digunakan menunjukan hasil yang lebih baik lagi. Penelitian ini akan melakukan prediksi harga listrik dengan menggunakan algoritma Neural Network backpropagation dan menambahkan Bootstrap Aggregating (Bagging) untuk mengoptimalkan NN sehingga performa yang dihasilkan oleh NN menjadi lebih baik lagi.

Prediksi harga listrik diharapkan akan menjadi sebuah penunjang keputusan dalam hal ini pemegang kebijakan khususnya dibidang kelistrikan untuk dapat mengetahui prediksi awal harga listrik sebelum menetapkan hargi listrik di pasaran.

\section{METODOLOGI}

\subsection{Dataset}

Penerapan Neural Network dengan penambahan bagging, dilakukan untuk dapat meningkatkan akurasi prediksi untuk memprediksi harga listrik dengan menggunakan 
dataset yang berasal dari NYISO data harga listrik di Amerika Serikat wilayah New York (www.nyiso.com) yang diambil dalam kurun waktu tiga bulan, yaitu mulai tanggal 1 Oktober 2014 sampai dengan 31 Desember 2014 yang terdiri dari 2209 record data. Dataset real terdiri dari 4 atribut yaitu Time stamp (tanggal dan waktu), name (penyedia layanan NYISO), PTID (kode NYISO) dan LBMP (harga listrik) seperti pada Tabel 1.

Tabel 1. Bentuk tabel yang digunakan

\begin{tabular}{cccc}
\hline Time Stamp & Name & PTID & $\begin{array}{c}\text { LBMP } \\
\text { (\$MWHr) }\end{array}$ \\
\hline 1/10/2014 0:00 & NYISO_LBMP_REFERENCE & 24008 & 28.86 \\
1/10/2014 1:00 & NYISO_LBMP_REFERENCE & 24008 & 29.68 \\
1/10/2014 2:00 & NYISO_LBMP_REFERENCE & 24008 & 25.63 \\
1/10/2014 3:00 & NYISO_LBMP_REFERENCE & 24008 & 24.37 \\
1/10/2014 4:00 & NYISO_LBMP_REFERENCE & 24008 & 23.04 \\
1/10/2014 5:00 & NYISO_LBMP_REFERENCE & 24008 & 20.27 \\
1/10/2014 6:00 & NYISO_LBMP_REFERENCE & 24008 & 12.01 \\
1/10/2014 7:00 & NYISO_LBMP_REFERENCE & 24008 & 21.44 \\
1/10/2014 8:00 & NYISO_LBMP_REFERENCE & 24008 & 18.25 \\
1/10/2014 9:00 & NYISO_LBMP_REFERENCE & 24008 & 56.44 \\
1/10/2014 10:00 & NYISO_LBMP_REFERENCE & 24008 & 39.67 \\
1/10/2014 11:00 & NYISO_LBMP_REFERENCE & 24008 & 28.98 \\
1/10/2014 12:00 & NYISO_LBMP_REFERENCE & 24008 & 29.67 \\
$\ldots$ & $\ldots$ & $\ldots$ & $\ldots$ \\
$\ldots$ & $\ldots$ & $\ldots$ & $\ldots$ \\
12/31/2014 22:00 & NYISO_LBMP_REFERENCE & 24008 & 11.61 \\
12/31/2014 23:00 & NYISO_LBMP_REFERENCE & 24008 & 12.01 \\
\hline
\end{tabular}

\subsection{Tahapan Eksperimen}

Pada penelitian ini, beberapa tahapan digunakan dalam ekperimen untuk mendapatkan sebuah model untuk meningkatkan tingkat akurasi Neural Network dengan menggunakan bagging, adapun metode yang diusulkan pada penelitian ini adalah seperti pada Gambar 1. 


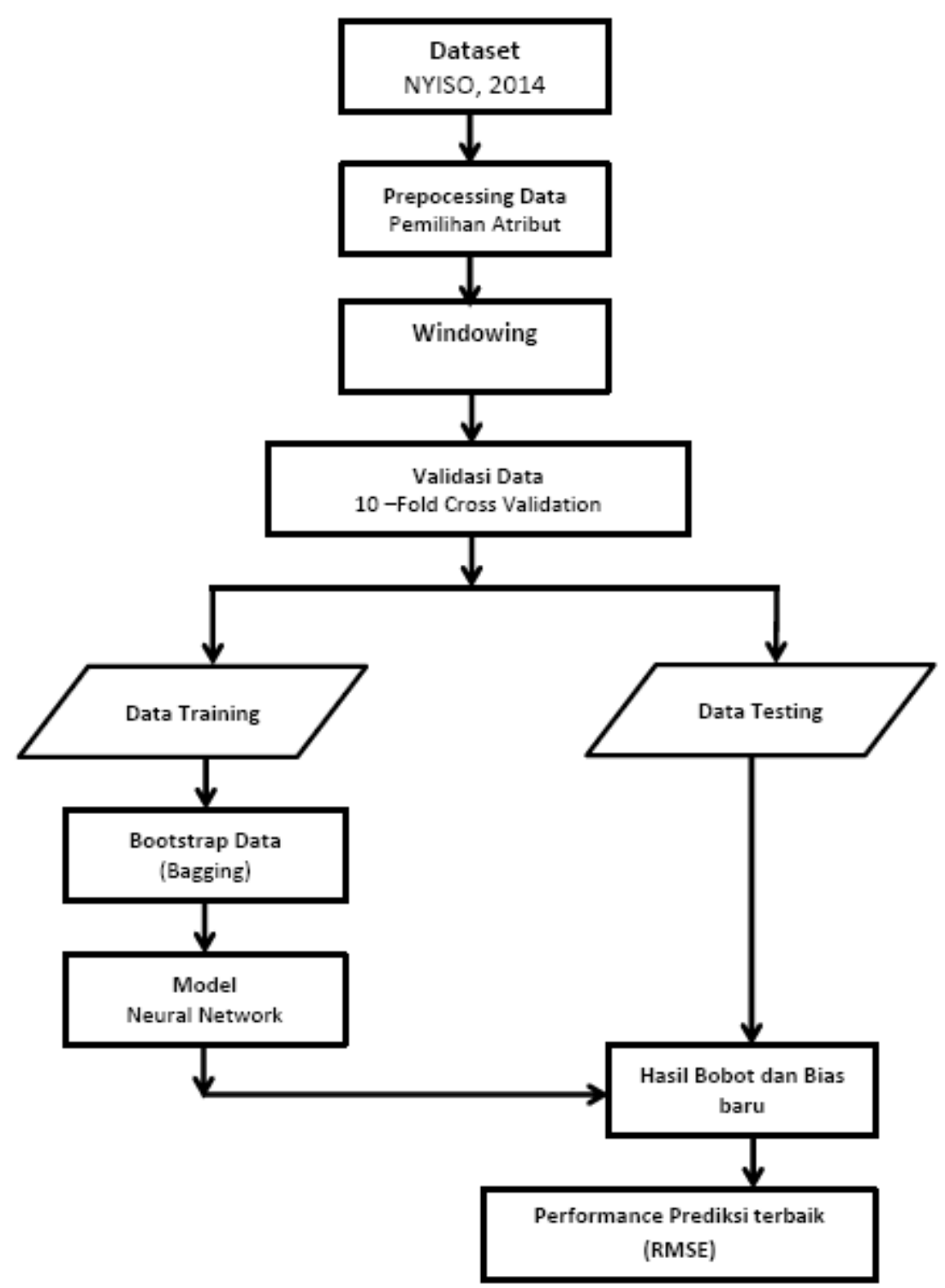

Gambar 1. Metode yang diusulkan

Seperti yang telihat pada Gambar 1, metode yang diusulkan adalah penerapan bagging pada Neural Network. Dataset yang berasal dari NYISO kemudian dilakukan pemilihan atribut yang sesuai yang diinginkan sehingga menjadi univariate atributnya. Setelah itu dilakukan windowing untuk menjadikan dataset menjadi mulvariate yang nantinya akan dimasukan sebagai data testing dan data training pada model. Validasi data dilakukan dengan menggunakan 10 Fold Cross validation untuk mengetahui nilai performance prediction yaitu nilai Root Mean Sequared Error $(R M S E)$ dari model yang kita buat berdasarkan dataset yang diolah. Penerapan 
bagging dilakukan pada data training sebelum dimasukan kedalam Neural Network, bagging dilakukan untuk mendapatkan nilai bobot dan bias baru Neural Network untuk mendapatkan nilai akurasi yang lebih baik.

\section{HASIL DAN PEMBAHASAN}

\subsection{Preprocessing Data}

Pada tahapan ini sebelum dataset dimasukan kedalam model yang telah dibuat, terlebih dahulu dilakukan preprocessing data yaitu pemilihan atribut. Pada tahapan ini dilakukan pemilihan atribut yang sesuai dengan yang akan digunakan. Adapun setelah dilakukan pemilihan atribut yang sesuai terhadap dataset yang akan digunakan, maka hasilnya seperti pada Tabel 2.

Tabel 2. Dataset hasil pemilihan atribut

\begin{tabular}{|c|c|}
\hline Time Stamp & LBMP (\$/MWHr) \\
\hline 1/10/2014 0:00 & 28.86 \\
\hline 1/10/2014 1:00 & 29.68 \\
\hline 1/10/2014 2:00 & 25.63 \\
\hline 1/10/2014 3:00 & 24.37 \\
\hline 1/10/2014 4:00 & 23.04 \\
\hline 1/10/2014 5:00 & 20.27 \\
\hline 1/10/2014 6:00 & 12.01 \\
\hline 1/10/2014 7:00 & 21.44 \\
\hline 1/10/2014 8:00 & 18.25 \\
\hline 1/10/2014 9:00 & 56.44 \\
\hline 1/10/2014 10:00 & 39.67 \\
\hline 1/10/2014 11:00 & 28.98 \\
\hline 1/10/2014 12:00 & 29.67 \\
\hline$\cdots$ & $\cdots$ \\
\hline$\ldots$ & $\ldots$ \\
\hline 12/31/2014 22:00 & 11.61 \\
\hline 12/31/2014 23:00 & 12.01 \\
\hline
\end{tabular}

Diperlihatkan pada Tabel 2, dataset yang telah dipilih atribut yang sesuai dengan yang diinginkan dan yang akan digunakan, terdapat 2 variabel data yaitu Time Stamp dan LBMP (\$/MWHr) dan grafik gambaran datanya adalah seperti pada Gambar 2. 


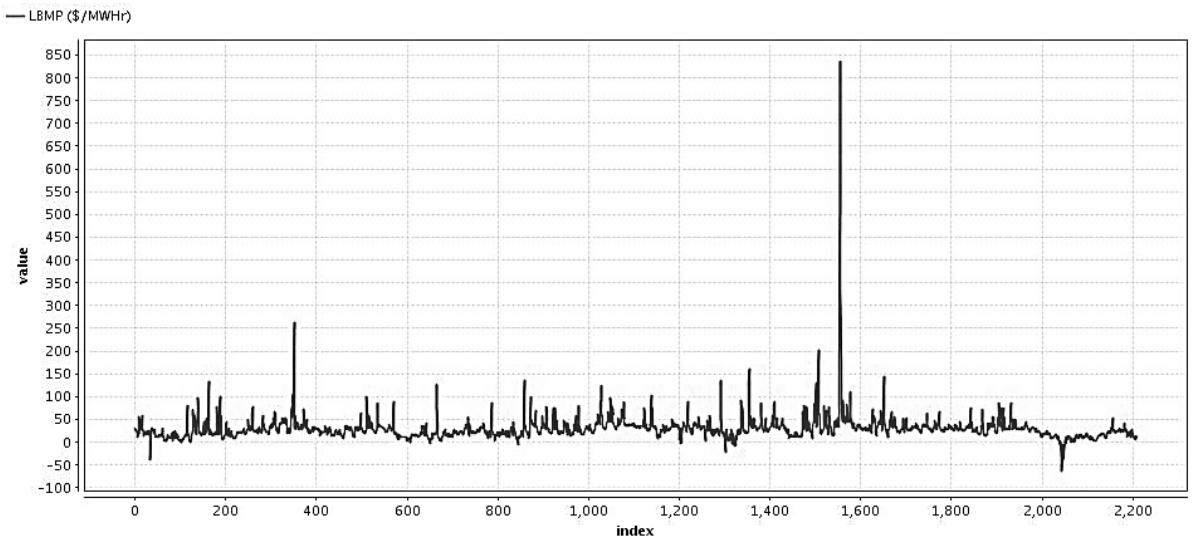

Gambar 2. Grafik data time series dataset, NYISO 2014

\subsection{Pengujian Model}

Penelitian yang dilakukan menggunakan komputer dengan spesifikasi processor $C P U$ Intel Core i5 $2.67 \mathrm{GHz}, R A M 4 \mathrm{~GB}$, serta sistem operasi Windows 7 Professional 32bit. Aplikasi yang digunakan adalah RapidMiner 5.3. Pada tahapan eksperimen pertama adalah dengan mencari jumlah windowing terbaik pada Neural Network, diperlihatkan pada Tabel 3.

Tabel 3. Hasil eksperimen pencarian windowing terbaik

\begin{tabular}{ccccc}
\hline windowing & $\begin{array}{c}\text { training } \\
\text { cycles }\end{array}$ & $\begin{array}{c}\text { learning } \\
\text { rate }\end{array}$ & momentum & RMSE \\
\hline 2 & 500 & 0.3 & 0.2 & $30.514+/-18.731$ \\
3 & 500 & 0.3 & 0.2 & $33.072+/-18.324$ \\
4 & 500 & 0.3 & 0.2 & $31.530+/-19.487$ \\
5 & 500 & 0.3 & 0.2 & $28.151+/-17.341$ \\
6 & 500 & 0.3 & 0.2 & $21.622+/-10.550$ \\
7 & 500 & 0.3 & 0.2 & $28.429+/-18.850$ \\
8 & 500 & 0.3 & 0.2 & $32.399+/-23.924$ \\
\hline
\end{tabular}

Berdasarkan hasil eksperimen pencarian jumlah windowing terbaik, maka didapatkan hasil windowing terbaik adalah 6 dengan hasil RMSE sebesar 21.622 +/- 10.550 seperti pada Tabel 3. Tahapan selanjutnya adalah mencari jumlah neuron hidden terbaik yang diterapkan pada model, adapun hasilnya adalah seperti pada Tabel 4.

Tabel 4. Hasil eksperimen neuron hidden terbaik

\begin{tabular}{ccccc}
\hline Hidden & $\begin{array}{c}\text { training } \\
\text { cycles }\end{array}$ & $\begin{array}{c}\text { learning } \\
\text { rate }\end{array}$ & momentum & RMSE \\
\hline 2 & 500 & 0.3 & 0.2 & $26.931+/-14.736$ \\
3 & 500 & 0.3 & 0.2 & $24.512+/-13.310$ \\
4 & 500 & 0.3 & 0.2 & $26.558+/-18.204$
\end{tabular}




\begin{tabular}{ccccc}
5 & 500 & 0.3 & 0.2 & $21.622+/-10.550$ \\
6 & 500 & 0.3 & 0.2 & $21.476+/-9.502$ \\
7 & 500 & 0.3 & 0.2 & $22.614+/-10.022$ \\
8 & 500 & 0.3 & 0.2 & $28.223+/-18.499$ \\
\hline
\end{tabular}

Pada Tabel 4 diperlihatkan hasil RMSE dengan jumlah neuron hidden terbaik pada Neural Network yaitu 6 neuron hidden dan mendapatkan RMSE sebesar 21.476 +/9.502 .

\subsection{Validasi dan Evaluasi Data}

Setelah didapatkan nilai RMSE yang terbaik yang didapatkan pada Neural Network, kemudian penelitian dilanjutkan dengan menerapkan bagging pada Neural Network. Parameter bagging ditetapkan parameter sample ratio $=0.9$ dan iteration $=10$. Setelah dilakukan eksperimen maka didapatkan hasilnya adalah seperti pada Tabel 5.

Tabel 5. Perbandingan NN dan NN+bagging

\begin{tabular}{ccc}
\hline & Algoritma & RMSE \\
\hline 1 & Neural Network & 21.476 \\
2 & Neural Network + Bagging & 10.513 \\
\hline
\end{tabular}

Berdasarkan hasil yang telah diperoleh, pada Tabel 5 diperlihatkan bahwa Neural Network dengan menggunakan bagging mempunyai tingkat akurasi yang lebih baik yaitu dengan nilai RMSE sebesar 10.513.

\section{SIMPULAN}

Penelitian dilakukan yaitu untuk mengoptimalisasi tingkat akurasi Neural Network untuk prediksi harga listrik diterapkan bagging sebagai model yang diusulkan. Dari hasil eksperimen yang telah dilakukan terlihat bahwa Neural Network dengan menggunakan bagging tingkat akurasi yang dihasilkan lebih baik dibandingkan dengan Neural Network tradisional yaitu yang semula mempunyai nilai RMSE sebesar 21.476 berubah menjadi nilai RMSE sebesar 10.513, maka hal ini membuktikan bahwa telah terjadi peningkatan tingkat akurasi prediksi. Meskipun model yang diusulkan telah memberikan sebuah peningkatan akurasi, tetapi untuk penelitian selanjutnya untuk menyempurnakan penelitian ini peningkatan akurasi prediksi untuk memprediksi harga listrik dengan menggunakan Neural Network optimalisasi sebaiknya dilakukan terlebih dahulu pengaturan parameter yang sesuai untuk mengurangi waktu pelatihan, serta dilakukan percobaan optimalisasi dengan menggunakan algoritma genetika (GA), PSO, Forward selection dan lain sebagainya sehingga model yang akan diusulkan dapat meningkatkan tingkat akurasi. 


\section{REFERENSI}

[1] Kaminski, V. 2013. Energy markets, Risk Books.

[2] Chen, X., Dong, Z. Y., Meng, K., Xu, Y., Wong, K. P., dan Ngan, H. W. 2012. Electricity price forecasting with extreme learning machine and bootstrapping. IEEE Transactions on Power Systems. Vol. 27(4): 2055-2062.

[3] B. R. Szkuta, L. A. Sanabria, and T. S. Dillon. 1999. Electricity price short-term forecasting using artificial Neural Networks. IEEE Trans. Power Syst. Vol. 14(3): 851-857.

[4] C. P. Rodriguez and G. J. Anders. 2004. Energy price forecasting in the Ontario competitive power system market. IEEE Trans. Power Syst. Vol. 19(1): 366374.

[5] Amjady, N. 2006. Day-ahead price forecasting of electricity markets by a new fuzzy Neural Network. IEEE Trans. Power Syst. Vol. 2(2): 887-896.

[6] Meng, K., Dong, Z.Y. \& Wong, K.P. 2009. Self-adaptive RBF Neural Network for short-term electricity price forecasting. IET Gen Transm Distrib. Vol. 3(4): 325-335.

[7] Dudoit, S., \& Fridlyand, J. 2003. Bagging to improve the accuracy of a clustering procedure. Bioinformatics. Vol. 19(9): 1090-1099.

[8] Tan, P.N., Steinbach, M. \& Kumar. 2006. Introduction to Data Mining 4th ed. Pearson Addison Wesley, Boston. 